The structural dynamics of social class

\author{
Michael W. Kraus
}

Jun Won Park

Yale University, School of Management 


\begin{abstract}
Individual agency accounts of social class persist in society and even in psychological science despite clear evidence for the role of social structures. This article argues that social class is defined by the structural dynamics of society. Specifically, access to powerful networks, groups, and institutions, and inequalities in wealth and other economic resources shape proximal social environments that influence how individuals express their internal states and motivations. An account of social class that highlights the means by which structures shape and are shaped by individuals guides our understanding of how people move up or down in the social class hierarchy, and provides a framework for interpreting neuroscience studies, experimental paradigms, and approaches that attempt to intervene on social class disparities.
\end{abstract}




\section{The structural dynamics of social class}

Take a moment to think of an eighth-grade student at an average public school in America who is excellent in mathematics, having scored in the top 25\% of students in the country on standardized math exams. This is the type of score that would qualify her for admission at a four-year college or university. However, the student is also from a lower social class background — her family has lower income, educational attainment, and occupational prestige than $75 \%$ of her classmates-effectively reducing her ability to access and utilize influential social networks, college preparatory services, and resources to cover college applications and expenses relative to her middle and upper class peers. What is the likelihood that she will graduate with a degree from a four-year college or university? Your answer depends on how much you think individuals can exercise personal agency in their interactions with and within existing social structures (e.g., schools and governments) to shape individual achievement outcomes. This line of thought also highlights a fundamental tension in research on social class in psychological science: What is the role of individuals and external structural forces in creating or altering a person's social position in society and its associations with cognition, emotion, and behavior?

Drawing on recent advances in the social and economic sciences, we suggest that the broadly construed field of psychology will benefit from a fuller consideration of precisely how class-based social structural forces-which we define as formal (e.g., state institutions, political parties, professions) and informal (e.g., social networks, groups, communities) social contexts that differ systematically in terms of social class position — shape and are shaped by individual psychological processes. More precisely, existing social structures create proximal contexts that individuals experience throughout their social and psychological development. The dynamic 
interplay between individual factors (e.g., motivation, personality, genes) and these proximate social structural forces, which we refer to as structural dynamics, best captures how social class contexts interact with individuals to shape their cognition, emotion, and behavior. Highlighting the structural dynamics of social class, rather than a purely structural or solely individual account, requires more nuanced interpretations of individual social class mobility, suggests caveats for neuroscientific studies and experimental manipulations of social class, and makes targeted recommendations for interventions aimed at reducing social class disparities in academic achievement outcomes. Social structures organize society in terms of many intersecting status dimensions (e.g., race, gender, ability, etc...), but in this article we focus primarily on the structures that shape individual psychological experiences of social class.

\section{The Structural Dynamics of Social Class and Class Mobility}

In prior work we and others have defined an individual's social class as having differing levels of social and economic resources and social rankings that arise as a result of the structural organization of society $(1,2,3,4 * *)$. Those at higher levels of social class contend with environments of, on average, more abundant economic resources, alongside socialization into influential networks, clubs, and business opportunities that build their social and cultural capital. In contrast, being at a lower level of the social class hierarchy exposes people more often to reduced resources, fewer connections with powerful groups, and increased contention with social and environmental threats (e.g., classism and discrimination, food insecurity, underemployment, reduced health coverage, fewer career advancement opportunities). These proximate conditions, we contend, create cultural learnings and persistent patterns of social cognition that shape social perceptions and individual behaviors. We distinguish this explanation of social class from a purely individualistic accounting of the construct in which individuals use a combination of skill 
The structural dynamics of social class 5

and motivation to shape their achievement outcomes, eventually sorting into the social class position in society, and accompanying rewards, that best match their skills, talents, and abilities (5).

Though the individual agency account of social class is a popular narrative (6), and examples of the influence of merit-based processes in education and hiring are easy to call to mind (c.f., 7-10), empirical evidence nevertheless highlights the imperfect nature of social class hierarchies: For instance, many educational systems have structures (e.g., economic disparities in school funding) favoring children from more-educated families even when merit and aptitude are held constant. In the United States (see Figure 1), analysis of National Education Survey data finds that only $28.8 \%$ of high aptitude students from relatively lower social class families earn four-year degrees, whereas that number is $74.1 \%$ among high aptitude students from higher social class families. Though high-aptitude students outperform lower aptitude ones in each social class group, this $45 \%$ difference in college graduation rates among the high aptitude students highlights the inherent limits of individual talents in shaping social class outcomes (11).

The resulting structural dynamics lead to relatively fewer opportunities for social class advancement for those who start out at the bottom of the class hierarchy: Less than 1\% of people born into the bottom income quintile in America move into the top quintile during their lifetime (12) and less than 3\% of students at four-year colleges come from the bottom income quintile (13). This lack of social class mobility is compounded for many ethnic minority families, who continue to experience reduced access to educational and economic opportunities relative to White families $\left(14^{* *}\right)$. Together these data are suggestive of the role of structural forces in constraining an individual's capacity to create or alter their own social class. 
The structural dynamics of social class 6

Within our field of psychology, researchers often wrestle with the interplay between individual capacities and social structures in work on the genetic determinants of intelligence and academic achievement. In this work, general intelligence has emerged as both a highly genetically determined trait as well as a strong predictor of educational outcomes (15-16). A cursory examination of this research might bolster an essentialist account of social class, that genetic factors solely determine achievement outcomes and downstream position in the social class hierarchy.

But this purely individual analysis fails to fully account for the structural dynamics of social class—in this particular case, how proximate social class environments might influence the expression of genetic predispositions for something like intelligence. A collection of twin studies are informative in this regard. In twin studies, monozygotic (MZ) and dizygotic (DZ) twins from low and high social class neighborhoods are compared on intelligence assessments and heritability, the amount of variance in a phenotype explained by genes, is calculated. In a meta-analysis examining 10,831 pairs of twins in the United States the heritability of intelligence was lower among lower social class environments than it was in higher social class environments $\left(17^{* *}\right)$. In essence, structural features of lower social class environments (e.g., lower access to high-quality education and health benefits) suppress the impact of genes on intelligence, and in particular, do not allow individuals lower in the class hierarchy to express their potential. Epigenetic studies of early social class environments find similar patterns: In these studies, early environments of lower, versus higher, resources tend to switch on genes that reduce the efficiency of the immune system, exposing children who happen to be lower in social class disproportionately to disease vulnerabilities that may constrain the development of intelligence (18). Overall, these studies suggest that social structures influence individual behaviors directly 
through constraining access to available resources, networking opportunities, and contact with powerful actors and groups. Social structures are also dynamic in that they indirectly influence individual behaviors by regulating the suppression or expression of behaviors and attributes that are then used to determine educational and achievement outcomes.

A dynamic account of social class must also acknowledge the role of individuals in maintaining the existing class hierarchy through a number of channels $(19 *, 20)$. Recent research indicates that people tend to affiliate less with others who have different social class backgrounds, particularly at the extremes of the social class spectrum (21) —and this kind of ingroup favoritism (22) reserves resource-rich relationships and relationship-based opportunities for those higher in social class. Other work indicates that people-presumably because resources serve as a proxy for competence—-selectively share less with low- versus high-resource others (23-24). As well, people both at the top and bottom of the class hierarchy are motivated to believe that the hierarchy is fair (25). For those at the bottom, fairness beliefs enhance striving because they support the presumption that efforts will be rewarded (26) whereas for those at the top, fairness beliefs suggest to high status individuals that their position in society is justified (6). Thus, individuals can play a role in affirming and reinforcing the social structures that maintain the prevailing class hierarchy through a combination of intergroup dynamics and motivational biases. Taken together, one begins to see the remarkable complexity that characterizes how individuals interact with, shape, and are shaped by social structures.

\section{Social Class in Neuroscience, Experiments, and Interventions}

A structural dynamics account of social class has direct implications for interpreting psychological examinations of social class in neuroscience studies, experimental paradigms, and intervention approaches to social class disparities. Scholars have long studied associations 
The structural dynamics of social class 8

between social class and cognitive functioning (27), and recent research has begun to examine differences in social class at the level of local brain activation. For instance, a recent study found that increased Mu-suppression in the motor cortex was higher among lower relative to higher social class participants while observing action-based pictures $\left(28^{*}, 29^{* *}\right)$, while an FMRI study found that participants who happen to be lower in social class showed greater activation in the mentalizing network when viewing pictures of people that included social information relative to higher social class participants (30). Together this research supports the hypothesis that lower social class environments engender greater brain activation in response to the social intentions of others, and aligns with previous work indicating that lower social class individuals are more collectively inclined (31, 32), more aware of others' mental states (33), and more compassionate in comparison to their higher social class counterparts (34). Given our analysis above, we caution against explaining these neuroscience findings solely in terms of innate configurations of the brain and body. Instead, a structural dynamics account of social class might consider how proximate environments create differential levels of need for mental state awareness, and as a result, adjust the brain and body configurations that support those mental processes (e.g., 29**, 35).

In recent efforts to understand the causal mechanisms of the influence of social class on basic psychology, researchers are more frequently using experimental approaches—-temporarily manipulating an aspect of the experience of social class, such as feelings of resource scarcity (36) or relative position in society $(37,38)$ before assessing psychological correlates of social class. For instance, just as lower-class individuals report greater trait-level hostile emotions and moods (39), temporarily getting a person to think of themselves as lower (versus higher) in social class position in society by manipulating comparisons to a person at the top or bottom of the 
The structural dynamics of social class 9

class hierarchy induces elevated hostility in ambiguous social settings (38, 40*). As another example, the many documented differences in executive functioning (27) associated with lower social class can be induced in experiments that modulate participant status at their university (41), or that expose participants to situations where they have lower, versus higher, levels of a particular valued resource $(42 *)$.

We advocate for the use of experimental methods for understanding the specific ingredients of proximate environments that influence class-based psychology. Notably, experimental methods highlight how social class is not solely housed within individuals but experienced by these individuals as they respond to the proximate social context. However, one important caveat of this work is that experimental manipulations are likely to be temporary in nature: As participants leave laboratory settings the external structures that occupy their lives snap back into existing configurations $\left(43^{* *}\right)$.

Studies that intervene on social class achievement outcomes also benefit from attention to the structures that undergird social class. In one example, researchers used an 8-week training program aimed at boosting selective attention, an important skill for educational proficiency, in an effort to boost the educational outcomes of students from relatively lower social class family backgrounds (44). Though the program showed immediate improvement in attention among treatment participants relative to active control groups, we are skeptical of the long-term efficacy of such interventions given our interpretation of social class: Specifically, the capacity for an individual characteristic to overcome the structural dynamics of social class is limited given the myriad ways that structures play a role in creating educational disparities (e.g., K-12 school funding, family economic hardships, alumni connections). The impact of individual aptitudes and skills may be diminished when facing these structures across time. 
Intervention strategies proposed in psychological science also disproportionately fall on those from lower social class backgrounds, indirectly suggesting that these individuals are deficient in some of the personal characteristics they need for success, and responsible for mitigating these deficiencies, rather than interacting with structures that put them at a disadvantage. For instance, researchers have proposed increasing parental nurturance to combat lower scores on neuropsychological assessments of cognitive functioning (45)—-the implication being that structural deficits in social resources, access, and influence can be mitigated through the heroic efforts of parents on their own. Without considering class-based structures, interventions run the risk of treating only the symptoms of inequality.

Relatedly, researchers may wish to propose structural interventions that modify the top of the social class hierarchy, through the activation of policies and norms that, for instance, limit the extent that managers use social class information as a proxy for competence in hiring decisions $\left(46^{* *}\right)$ or that provide students with more access to the social and economic resources and opportunities that are not endemic, on average, to lower social class environments $\left(47,48^{*}, 49\right)$. On this latter case, in countries that provide more uniform access to high-quality education and health care across the social class spectrum (e.g., Australia), social class environments do not moderate genetic associations with intelligence $\left(17^{* *}\right)$. Whatever the strategy, a psychological science that focuses on structural dynamics — where individuals interact with class-based systems - is best positioned to identify effective intervention strategies for reducing social class disparities.

Our analysis here suggests that purely individual accounts of social class achievement, such as popular accounts of the American Dream, do not match with the available empirical evidence. Nevertheless, people are motivated to see society as fair, just, and merit-based (6-9), 
and so these individualistic accounts of social class will persist in public discourse and in research. Demonstrating the allure of individualistic accounts, in his early work one of the authors of this manuscript wrote that heightened perceived control might buffer relatively lowerclass children from poor health and emotional distress (50)_a claim that a structural dynamics account of social class calls into question. Psychological science can contribute more to the science of social class to the extent that it highlights how social structures that define social class interact with an individual's psychology to shape and constrain the social and economic opportunities sought by individuals.

We hope that the arguments here can help to remind researchers that social structures loom large in the lives of individuals, and that these structures can shape the capacity for individuals to express their innate abilities and constrain the influence that individuals have over the economic and social outcomes they achieve across the life course. Given that individualistic accounts of social class tend to appear frequently in discussions among policymakers (51), a psychological science that considers the structural dynamics of social class more fully is poised to contribute to these policy discussions. 


\section{References}

1. Stephens, N. M., Markus, H. R., \& Fryberg, S. A. (2012). Social class disparities in health and education: Reducing inequality by applying a sociocultural self model of behavior. Psychological review, 119(4), 723-744.

2. Kraus, M. W., Piff, P. K., Mendoza-Denton, R., Rheinschmidt, M. L., \& Keltner, D. (2012). Social class, solipsism, and contextualism: how the rich are different from the poor. Psychological Review, 119(3), 546-572.

3. Cohen, A. B., \& Varnum, M. E. W. (2016). Beyond east vs. west: Social class, region, and religion as forms of culture. Current Opinion in Psychology, 8, 5-9.

4. **Destin, M., Rheinschmidt-Same, M., \& Richeson, J.R. (2017). Status-based identity: A conceptual framework integrating the social psychological study of socioeconomic status and identity. Perspectives on Psychological Science, 12(2), 270-289.

In this article, the authors highlight the role of social identity in the experience of social class. Social identity is likely to be a particularly fruitful avenue by which to view social class because identity highlights how individual traits and beliefs are shaped by current and past relationships of individuals to the structural organization of society.

5. Durkheim, E. (1933). The division of labor in society. (1994) New York: MacMillan.

6. Kraus, M. W., \& Tan, J. J. (2015). Americans overestimate social class mobility. Journal of Experimental Social Psychology, 58, 101-111.

7. Davidai, S., \& Gilovich, T. (2015). Building a more mobile America-One income quintile at a time. Perspectives on Psychological Science, 10(1), 60-71. 
8. Day, M. V. \& Fiske, S. T. (2017). Movin’ on up? How perceptions of social mobility affect our willingness to defend the system. Social Psychological and Personality Science, 8(3), 267-274.

9. Shariff, A. F., Wiwad, D., \& Aknin, L.B. (2016). Income mobility breeds tolerance for income inequality: Cross-national and experimental evidence. Perspectives on Psychological Science. 11, 373-380.

10. Gould, R. V. (2002). The origins of status hierarchies: A formal theory and empirical test. American journal of sociology, 107(5), 1143-1178.

11. Fox, M. A., Connolly, B. A., \& Snyder, T. D. (2005). Youth indicators, 2005: Trends in the well-being of American youth. NCES 2005-050. US Department of Education.

12. Economic Policy Institute, State of Working America Data Library, "Compensation, wages, and benefits,” 2017.

13. Carnevale, A. P., \& Rose, S. J. (2003). Socioeconomic Status, Race/Ethnicity, and Selective College Admissions. A Century Foundation Paper.

14. *Richeson, J. A., \& Sommers, S. R. (2016). Toward a social psychology of race and race relations for the twenty-first century. Annual review of psychology, 67, 439-463.

We do not have sufficient space in this review to delve into intersections between race and social class but this intersection is at the very crux of a structural understanding of social class. This is the best paper, we know of, to delve deeply into the implications of race-based economic inequality for intergroup relations. Importantly, the paper suggests that an 
account of race that is faithful to historical and structural causes will lead to a more informed psychological science. We apply this logic directly to studies of social class.

15. Gottfredson, L. S. (2004). Intelligence: is it the epidemiologists' elusive" fundamental cause" of social class inequalities in health?. Journal of Personality and Social Psychology, 86(1), 174-199.

16. Okbay, A., Beauchamp, J. P., Fontana, M. A., Lee, J. J., Pers, T. H., Rietveld, C. A., ... \& Oskarsson, S. (2016). Genome-wide association study identifies 74 loci associated with educational attainment. Nature, 533(7604), 539-542.

17. *Tucker-Drob, E. M., \& Bates, T. C. (2016). Large Cross-National Differences in Gene× Socioeconomic Status Interaction on Intelligence. Psychological science, 27(2), 138.

This meta-analysis is the most comprehensive evidence for the dynamic interplay between individual genes and structural contexts of social class. In particular, the cross-national comparison between the United States and countries like Australia is suggestive of the possible role that broad policies related to education and healthcare access have in the development of social class differences in individual characteristics like intelligence.

18. Powell, N. D., Sloan, E. K., Bailey, M. T., Arevalo, J. M., Miller, G. E., Chen, E., ... \& Cole, S. W. (2013). Social stress up-regulates inflammatory gene expression in the leukocyte transcriptome via $\beta$-adrenergic induction of myelopoiesis. Proceedings of the National Academy of Sciences, 110(41), 16574-16579.

19. **Kraus, M. W., Park, J. W., \& Tan, J. J. X. (2017). Signs of social class: The experience of economic inequality in everyday life. Perspectives on Psychological Science, 12(3), 422435. 
In this paper we suggest that social class shapes many social interactions in ways that perpetuate the structural dynamics of social class. In particular, we highlight precisely how segregated society is in terms of social class, and the implications of that segregation for cooperation and resource sharing.

20. Becker, J. C., Kraus, M. W., \& Rheinschmidt-Same, M. (2017). Cultural Expressions of Social Class and Their Implications for Group-Related Beliefs and Behaviors. Journal of Social Issues, 73(1), 158-174.

21. Côté, S., Kraus, M. W., Carpenter, N. C., Piff, P. K., Beermann, U., \& Keltner, D. (2017). Social affiliation in same-class and cross-class interactions. Journal of Experimental Psychology: General, 146(2), 269-285.

22. Tajfel, H., \& Turner, J. C. (1979). An integrative theory of intergroup conflict. The social psychology of intergroup relations, 33(47), 74.

23. Nishi, A., Shirado, H., Rand, D. G., \& Christakis, N. A. (2015). Inequality and visibility of wealth in experimental social networks. Nature, 526(7573), 426-429.

24. Sands, M. L. (2017). Exposure to inequality affects support for redistribution. Proceedings of the National Academy of Sciences, 201615010.

25. Lipkus, I. (1991). The construction and preliminary validation of a global belief in a just world scale and the exploratory analysis of the multidimensional belief in a just world scale. Personality and Individual Differences, 12(11), 1171-1178. 
26. Haselton, M. G., Bryant, G. A., Wilke, A., Frederick, D. A., Galperin, A., Frankenhuis, W. E., \& Moore, T. (2009). Adaptive rationality: An evolutionary perspective on cognitive bias. Social Cognition, 27(5), 733-763.

27. Hackman, D. A., \& Farah, M. J. (2009). Socioeconomic status and the developing brain. Trends in cognitive sciences, 13(2), 65-73.

28. **Varnum, M. E. W.(2016). The emerging (social) neuroscience of SES. Social and Personality Psychology Compass, 10, 423-430.

This review provides a comprehensive examination of recent efforts to study social class differences in cognition, motivation, and perception using social neuroscience tools like fMRI and ERP. Importantly the manuscript describes interpretation challenges inherent in a biological approach to social structural differences.

29. *Varnum, M. E., Blais, C., \& Brewer, G. A. (2016). Social class affects Mu-suppression during action observation. Social Neuroscience, 11(4), 449-454.

Social class differences that occur in the brain and body are difficult to describe without essentializing social class as located within the genetic material of individuals. This paper does a particularly excellent job of avoiding this problem in its explanations and future directions for research. The main findings indicate that Mu-suppression during action observation is stronger for those who are relatively lower than higher in socioeconomic status. The findings have direct implications for how much individuals attend to the actions of others based on their position in society. 
30. Muscatell, K. A., Morelli, S. A., Falk, E. B., Way, B. M., Pfeifer, J. H., Galinsky, A. D., ... \& Eisenberger, N. I. (2012). Social status modulates neural activity in the mentalizing network. Neuroimage, 60(3), 1771-1777.

31. Snibbe, A. C., \& Markus, H. R. (2005). You can't always get what you want: educational attainment, agency, and choice. Journal of personality and social psychology, 88(4), 703.

32. Stephens, N. M., Markus, H. R., \& Townsend, S. S. (2007). Choice as an act of meaning: the case of social class. Journal of personality and social psychology, 93(5), 814.

33. Kraus, M. W., Côté, S., \& Keltner, D. (2010). Social class, contextualism, and empathic accuracy. Psychological Science, 21(11), 1716 - 1723.

34. Stellar, J. E., Manzo, V. M., Kraus, M. W., \& Keltner, D. (2012). Class and compassion: socioeconomic factors predict responses to suffering. Emotion, 12(3), 449.

35. Varnum, M. E., Na, J., Murata, A., \& Kitayama, S. (2012). Social class differences in N400 indicate differences in spontaneous trait inference. Journal of Experimental Psychology: General, 141(3), 518 - 526.

36. Mullainathan, S., \& Shafir, E. (2013). Scarcity: The new science of having less and how it defines our lives. New York: Picador

37. Callan, M. J., Ellard, J. H., Shead, N. W., \& Hodgins, D. C. (2008). Gambling as a search for justice: Examining the role of personal relative deprivation in gambling urges and gambling behavior. Personality and Social Psychology Bulletin, 34, 1515-1529. 
38. Kraus, M. W., Horberg, E. J., Goetz, J. L., \& Keltner, D. (2011). Social class rank, threat vigilance, and hostile reactivity. Personality and Social Psychology Bulletin, 37(10), 1376-1388.

39. Gallo, L. C., \& Matthews, K. A. (2003). Understanding the association between socioeconomic status and physical health: do negative emotions play a role? Psychological Bulletin, 129(1), 10-51.

40. *Greitemeyer, T., \& Sagioglou, C. (2016). Subjective socioeconomic status causes aggression: A test of the theory of social deprivation. Journal of Personality and Social Psychology, 111(2), 178-194.

The manuscript presents experimental work that manipulates the extent people are made to feel temporarily low or high in a social class hierarchy. Following this manipulation, manipulated lower social class participants were more aggressive toward a high status experiment partner relative to their manipulated higher social class counterparts.

41. Johnson, S. E., Richeson, J. A., \& Finkel, E. J. (2011). Middle class and marginal? Socioeconomic status, stigma, and self-regulation at an elite university. Journal of Personality and Social Psychology, 100(5), 838-852.

42. *Shah, A. K., Shafir, E., \& Mullainathan, S. (2015). Scarcity frames value. Psychological Science, 26(4), 402-412.

In experimental work, people under conditions of scarcity focus more on pressing needs and recognize trade-offs between these needs and future goals. Under conditions of abundance people do not as easily recognize these values trade-offs. 
43. *Sen, M., \& Wasow, O. (2016). Race as a Bundle of Sticks: Designs that Estimate Effects of Seemingly Immutable Characteristics. Annual Review of Political Science, 19, 499-522.

In this article, political scientists suggest that race is best conceptualized as a collection of related constructs or "bundle of sticks" and we tend to ascribe the same logic to social class. Thus, experimental manipulations of social class merely assess the modulation of one particular correlate of social class and its resultant causal influence on downstream psychological outcomes.

44. Neville, H. J., Stevens, C., Pakulak, E., Bell, T. A., Fanning, J., Klein, S., \& Isbell, E. (2013). Family-based training program improves brain function, cognition, and behavior in lower socioeconomic status preschoolers. Proceedings of the National Academy of Sciences, 110(29), 12138-12143.

45. Farah, M. J., Betancourt, L., Shera, D. M., Savage, J. H., Giannetta, J. M., Brodsky, N. L., ... \& Hurt, H. (2008). Environmental stimulation, parental nurturance and cognitive development in humans. Developmental science, 11(5), 793-801.

46. **Rivera, L. A. (2016). Pedigree: How elite students get elite jobs. Princeton University Press.

In this book, the author discusses how corporations select among job applicants based on an examination of personal and social characteristics in an effort to find applicants who fit company culture. This effort has the unintended consequence of perpetuating social class inequalities in hiring and promotion.

47. Stephens, N. M., Hamedani, M. G., \& Destin, M. (2014). Closing the social-class achievement gap a difference-education intervention improves first-generation students’ 
academic performance and all students’ college transition. Psychological science, 25(4), 943-953.

48. *Jury, M., Smeding, A. Stephens, N. M., Nelson, J., Aelenei, C., \& Darnon, C. (2017). The experience of Low-SES students in higher education: Psychological barriers to success and interventions to reduce social-class inequality. Journal of Social Issues, 73(1), 16-34. doi: 10.1111/josi.12202

This review article highlights the psychological barriers faced more by lower socioeconomic students in higher education compared to their higher SES counterparts. The manuscript does a particularly good job of highlighting how social structures create contexts that reproduce these psychological barriers along with highlighting possible ways to intervene.

49. Browman, A. S., \& Destin, M. (2016). The Effects of a Warm or Chilly Climate Toward Socioeconomic Diversity on Academic Motivation and Self-Concept. Personality and Social Psychology Bulletin, 42, 172-187.

50. Kraus, M. W., Piff, P. K., \& Keltner, D. (2009). Social class, sense of control, and social explanation. Journal of Personality and Social Psychology, 97(6), 992-1004.

51. Ryan, P. (2017). A better way: Our vision for a confident America. Retrieved from: http://abetterway.speaker.gov 
Figure 1. The share of students completing four-year college degrees as a function of socioeconomic status, a composite that includes family income, parental education, and parental occupation, and eighth-grade mathematics standardized test scores (11). A purely individual account would predict equal college degree attainment for students of equal aptitude, whereas a purely structural influence account would predict that high social class children earn the majority of four-year college degrees regardless of aptitude. Data are reproduced under a creative commons license.

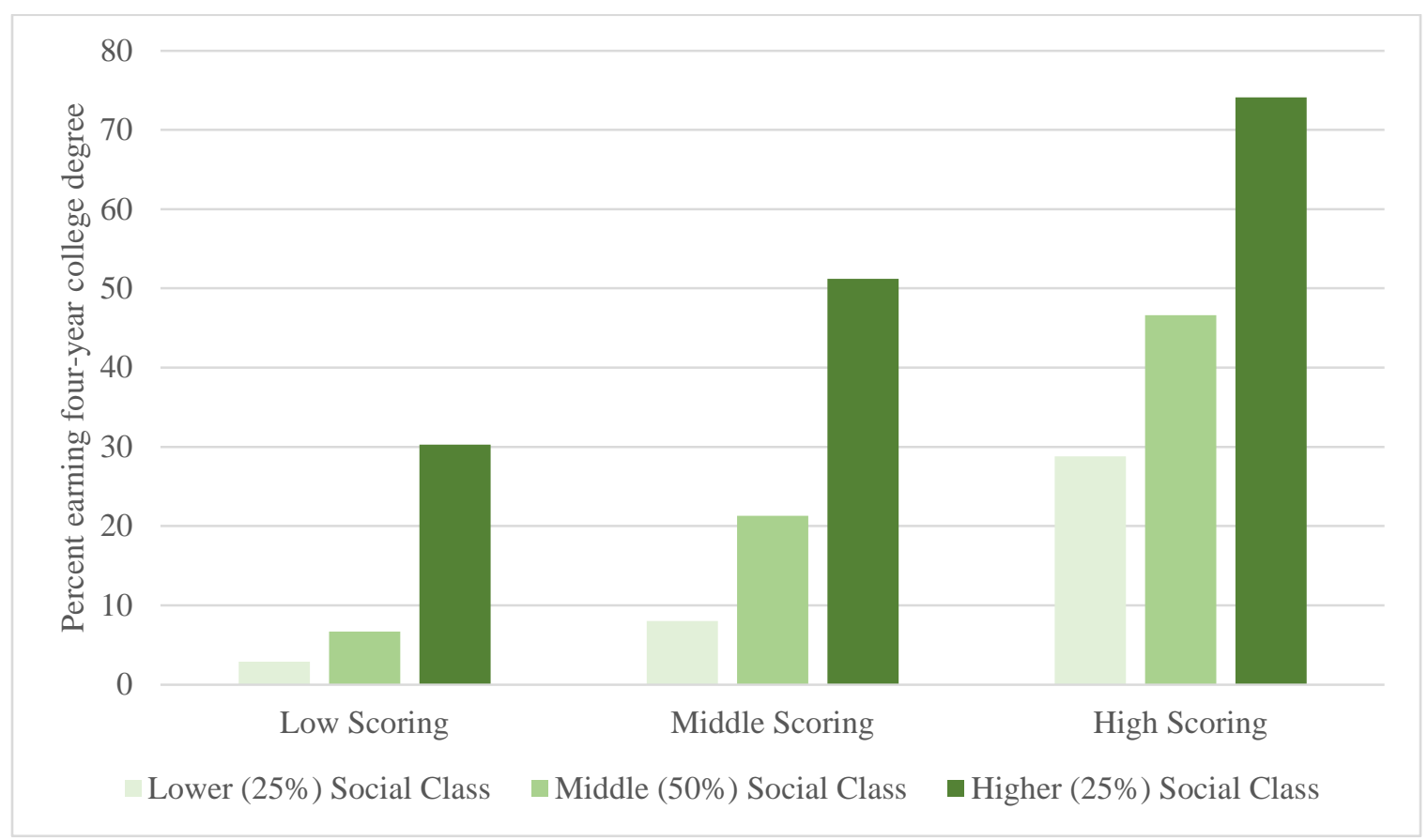

